\title{
Gender stereotypes in occupational choice: a cross-sectional study on a group of Italian adolescents [Erratum]
}

\author{
Ramaci T, Pellerone M, Ledda C, Presti G, Squatrito V, Rap- \\ isarda V. Psychol Res Behav Manag. 2017;10:109-117. \\ On page 116, Reference section, an error was introduced in \\ the numbering regarding reference 44 . \\ The correct reference details are: \\ 44. Wraga M, Duncan L, Jacobs EC, Helt M, Church J. Stereotype suscep- \\ tibility narrows the gender gap in imagined self-rotation performance. \\ Psychon Bull Rev. 2006;13(5):813-819.
}

The reference citation in the main text is correct. 